\section{BMJ Global Health}

\title{
Safer primary healthcare facilities are needed to protect healthcare workers and maintain essential services: lessons learned from a multicountry COVID-19 emergency response initiative
}

\author{
Leena N Patel, ${ }^{1}$ Samantha Kozikott, ${ }^{1}$ Rodrigue Ilboudo, ${ }^{2}$ Moreen Kamateeka, ${ }^{3}$ \\ Mohammed Lamorde, ${ }^{4}$ Marion Subah, ${ }^{5}$ Fatima Tsiouris, ${ }^{6}$ Anna Vorndran, ${ }^{7}$ \\ Christopher T Lee, ${ }^{1}$ On behalf of the African Primary Health Care IPC \\ Strengthening Community of Practice
}

\begin{abstract}
To cite: Patel LN, Kozikott S, Ilboudo R, et al. Safer primary healthcare facilities are needed to protect healthcare workers and maintain essential services: lessons learned from a multicountry COVID-19 emergency response initiative. BMJ Global Health 2021;6:e005833. doi:10.1136/ bmjgh-2021-005833
\end{abstract}

Handling editor Seye Abimbola

- Additional supplemental material is published online only. To view, please visit the journal online (http://dx.doi.org/10. 1136/bmjgh-2021-005833).

Received 25 March 2021 Revised 22 April 2021 Accepted 3 May 2021
Check for updates

\section{(C) Author(s) (or their} employer(s)) 2021. Re-use permitted under CC BY-NC. No commercial re-use. See rights and permissions. Published by BMJ.

For numbered affiliations see end of article.

\section{Correspondence to} Dr Christopher T Lee; clee@resolvetosavelives.org

\section{ABSTRACT}

Healthcare workers (HCWs) are at increased risk of infection from SARS-CoV-2 and other disease pathogens, which take a disproportionate toll on HCWs, with substantial cost to health systems. Improved infection prevention and control (IPC) programmes can protect HCWs, especially in resource-limited settings where the health workforce is scarcest, and ensure patient safety and continuity of essential health services. In response to the COVID-19 pandemic, we collaborated with ministries of health and development partners to implement an emergency initiative for HCWs at the primary health facility level in 22 African countries. Between April 2020 and January 2021, the initiative trained 42058 front-line HCWs from 8444 health facilities, supported longitudinal supervision and monitoring visits guided by a standardised monitoring tool, and provided resources including personal protective equipment (PPE). We documented significant short-term improvements in IPC performance, but gaps remain. Suspected HCW infections peaked at $41.5 \%$ among HCWs screened at monitored facilities in July 2020 during the first wave of the pandemic in Africa. Disease-specific emergency responses are not the optimal approach. Comprehensive, sustainable IPC programmes are needed. IPC needs to be incorporated into all HCW training programmes and combined with supportive supervision and mentorship. Strengthened data systems on IPC are needed to guide improvements at the health facility level and to inform policy development at the national level, along with investments in infrastructure and sustainable supplies of PPE. Multimodal strategies to improve IPC are critical to make health facilities safer and to protect HCWs and the communities they serve.

\section{INTRODUCTION}

Healthcare workers (HCWs) are essential to maintaining individual and population health. Despite their critical importance, the

\section{Summary box}

Infection prevention and control (IPC) measures are essential to protect healthcare workers (HCWs), patients and communities from SARS-CoV-2 and other outbreaks.

- Despite this critical need, IPC measures are suboptimal around the world, especially in resource-limited settings with austere health systems, where barriers to effective IPC include limited workforce of trained IPC professionals, paucity of availability of personal protective equipment (PPE), and limited clinical infrastructure at the primary health facility level for required environmental controls and water and sanitation for safe health service delivery.

- In response to COVID-19, we designed an emergency intervention to address these constraints in 22 African countries by supporting rapid in-service training, systematic data collection and stopgap provision of PPE and other supplies. These interventions may have contributed to improved IPC capacity at primary healthcare facilities.

- Despite this short-term success, emergency response efforts are not an optimal way to strengthen IPC systems. Urgent attention is needed to ensure the development of national IPC policies, guidelines, training curricula, supportive supervision, and monitoring and evaluation systems. Domestic and global investments are needed to enhance health facility infrastructure and to ensure availability of adequate PPE and supplies to protect HCWs and the communities they serve.

WHO estimates a shortfall of 18 million HCWs by 2030 , mostly in low-income and middleincome countries (LMICs), ${ }^{1}$ making it imperative to recruit, train, support and retain additional HCWs. Effective implementation of infection prevention and control (IPC) 
programmes in healthcare settings is a global prioritynot only to protect the health and well-being of HCWs and the people they serve ${ }^{2}$ but also as a supporting mechanism for global health priorities to achieve universal health coverage. ${ }^{3}$

Weak IPC programmes and ineffective implementation pose a global challenge affecting all aspects of health system performance and contribute to hundreds of millions of healthcare-associated infections annually. ${ }^{4}$ Weak IPC programmes have also contributed to the disproportionate toll of recent epidemics on HCWs in both LMICs and high-income countries. HCWs were 21-32 times more likely than the general population to become infected with Ebola during the 2014-2015 West Africa Ebola epidemic, ${ }^{5}$ and $1 \%, 7 \%$ and $8 \%$ of the health workforce died from Ebola in Guinea, Sierra Leona and Liberia, respectively. ${ }^{6}$ During the 2003 SARS epidemic, HCWs comprised $21 \%$ of confirmed cases globally. ${ }^{7}$ HCWs are similarly at increased risk of SARS-CoV-2 infection. ${ }^{8-11}$ Early in the pandemic, the highest numbers of HCW infections were reported from Europe and the USA. ${ }^{12}$ HCWs represent $<3 \%$ of the global population but accounted for $14 \%$ of cases reported to the WHO as of September 2020. ${ }^{10} \mathrm{HCWs}$ accounted for $3.4 \%$ of infections in 46 WHO African region countries as of 11 April 2021. ${ }^{13}$ Data on the true burden of infection are needed. ${ }^{14}$

Protecting HCWs must be prioritised to minimise the direct impact on an already fragile health workforce as well as indirect impacts on essential health service delivery. The Ebola epidemic impacted all aspects of the health system due to HCW deaths, health facility closures, diversion of resources and staff, and decreased use of services, ${ }^{15}$ including those for maternal and child health, HIV and malaria. ${ }^{16}$

The COVID-19 pandemic has similarly affected health systems. Nearly all countries $(90 \%)$ surveyed by the WHO reported disruptions in essential health services, with more disruptions in LMICs. ${ }^{17}$ There were significant disruptions in care for non-communicable diseases ${ }^{17}$ and long-standing illnesses or health issues. ${ }^{18}$ Over $50 \%$ of countries limited outpatient services. ${ }^{17}$ Cancellation of elective care and deployment of clinical staff to pandemic response contributed to decreased availability of services. ${ }^{17}$ Reduced demand for services also contributed to disruptions; $76 \%$ of countries reported a decrease in patients presenting for care, ${ }^{17}$ and $45 \%$ of patients requiring services across 18 African countries delayed, skipped or were unable to obtain health services. ${ }^{18}$ Fear of COVID-19 infection was the most common reason for missing health visits. ${ }^{18}$ Similarly, fear of Ebola infection contributed to decreased use of services. ${ }^{19}$

A robust IPC programme is critical to help mitigate the impact of COVID-19 and other infectious pathogens on health systems, ${ }^{20-23}$ but gaps in IPC capacity and ineffective implementation pose challenges. First, IPC training is often limited in LMICs. ${ }^{24}{ }^{25} \mathrm{~A}$ WHO survey of 88 countries to assess implementation of the WHO core components of an IPC programme found that only $54 \%$ had in-service IPC training. ${ }^{26}$ Over half (18 of 32) of national nursing associations reported IPC training had not been provided within 6 months of the pandemic's start. ${ }^{27}$ Supportive supervision and mentorship for health facilities are also part of an effective IPC programme ${ }^{2}$ and contribute to improved quality of care and strengthened health systems. ${ }^{28}$ Yet access to IPC professionals is limited in most LMICs. ${ }^{29}$ Second, programme monitoring and systematic use of data are needed to identify persistent gaps and to implement evidence-based policies; however, only $66 \%$ (58 of 88 ) of WHO-surveyed countries monitored IPC-related indicators, with a lower proportion among LMICs. ${ }^{26}$ Third, limited resources and infrastructure in LMICs pose even greater challenges, ${ }^{29-32}$ and only $26 \%$ (23 of 88) of WHO-surveyed countries had a dedicated and protected IPC budget. ${ }^{26}$

\section{APPROACH TO DELIVERING AN IPC INITIATIVE}

During April 2020-January 2021, Resolve to Save Lives (RTSL), an initiative of Vital Strategies, which aims to prevent millions of deaths from cardiovascular disease and epidemics, partnered with ministries of health and implementing partners in 22 African countries to deliver a comprehensive programme of in-service training, monitoring at primary healthcare facilities and procurement of personal protective equipment (PPE) and other resources to improve IPC practices. Our implementing partners included non-governmental organisations, networks and academic institutions based in Africa or with significant experience working in Africa. Two implementing partners, Last Mile Health (LMH) and Infection Control Africa Network (ICAN), provided longitudinal mentorship and supportive supervision to health facilities.

The programme prioritised competencies in six key domains: (1) recognition and reporting of suspected COVID-19 cases; (2) safe universal screening and triage; (3) facility-based IPC; (4) water, sanitation, and hygiene (WASH); (5) communication with patients; and (6) maintenance of essential services. Implementing partners used this framework to design and/or adapt training modules to individual country contexts, in partnership with ministries of health. Countries had varying levels of COVID-19-related restrictions on travel and in-person gatherings, so each country selected an appropriate combination of in-person and virtual training. Drawing from existing global guidance, a best practices toolkit, ${ }^{33}$ which was later adapted and published by the Africa Centres for Disease Control and Prevention, ${ }^{34}$ was developed in both English and French based on the IPC hierarchy-source controls, administrative controls, environmental controls and $\mathrm{PPE}^{35}$-for use by implementing partners at primary healthcare settings.

To monitor IPC implementation at the health facility level, we developed a simple checklist (online supplemental materials) to assess IPC practices such as triage, COVID-19 surveillance and PPE availability. Implementing partners adapted the checklist in consultation with ministries of 
health/primary healthcare agencies to monitor performance and provide structured feedback to selected health facilities. Data on HCW behaviours were collected by LMH and ICAN as part of monitoring visits. The frequency of data collection was modified in coordination with ministries of health. Duration of data collection varied as programme scale-up occurred at different times in each country. Implementing partners submitted data to RTSL for review using a standard data quality tool; discrepancies and questions were discussed with implementing partners. We present data on the number of HCW trained in all 22 countries and data from a subset of nine countries $(41 \%)$ with available facility-level data and appropriate ethical and ministry approvals to publish. Facility-level data from 13 countries $(59 \%)$ were excluded from the analyses because data did not meet quality criteria; limited or no data were collected; and/or ministry of health approvals were not obtained. Data were dichotomised for analysis and we conducted a z-test of proportions to evaluate changes in IPC capacity after checking for assumptions of the appropriateness of the statistical test.
TRAINING, MENTORSHIP, AND SUPPORTIVE SUPERVISION FOR HCW BEHAVIOUR CHANGE

As COVID-19 continued to spread globally, few training packages for primary healthcare settings in resourcelimited environments existed; WHO guidance primarily targeted hospitals. Recognising the critical role of primary HCWs in providing care to communities and the importance of protecting them against COVID-19 infection, our implementing partners rapidly scaled this comprehensive initiative. Between April 2020 and January 2021, implementing partners trained 42058 HCWs from 8444 health facilities, including 7574 primary health facilities, across the 22 countries (table 1 ).

Health facilities in Liberia received longitudinal mentorship and supportive supervision from LMH. ICAN provided this support to selected health facilities in Cameroon, DRC, Ethiopia, Kenya, Liberia and Nigeria. Regular visits provided an opportunity to reinforce best practices, implement solutions for identified challenges and promote behaviour change. Data from 20 facilities in Lagos, Nigeria, found that at baseline, only $37 \%$ and $32 \%$ of HCWs correctly performed hand hygiene and appropriately used masks inside the health facilities,

\begin{tabular}{|c|c|c|c|}
\hline Country & Implementing partner & $\begin{array}{l}\text { Healthcare workers } \\
\text { trained }(n)\end{array}$ & $\begin{array}{l}\text { Health facilities trained }(\mathrm{n}) \\
\text { (primary health facilities, } \mathrm{n} \text { ) }\end{array}$ \\
\hline Angola & ICAP at Columbia University & 470 & $30(27)$ \\
\hline Burundi & ICAP at Columbia University & 398 & 316 (293) \\
\hline Cameroon & ALIMA & 465 & $153(139)$ \\
\hline Cote d'Ivoire & ICAP at Columbia University & 391 & $98(95)$ \\
\hline DRC & ALIMA & 1421 & $115(99)$ \\
\hline Eswatini & ICAP at Columbia University & 1145 & $37(19)$ \\
\hline Ethiopia & Ethiopian Medical Association & 4293 & $139(111)$ \\
\hline Ghana & Jhpiego & 1005 & $178(141)$ \\
\hline Kenya & ICAP at Columbia University & 1219 & $10(0)$ \\
\hline Lesotho & ICAP at Columbia University & 423 & $23(19)$ \\
\hline Liberia & Last Mile Health & 1538 & $87(87)$ \\
\hline Malawi & ICAP at Columbia University & 625 & $81(74)$ \\
\hline Mali & Muso & 2810 & $1916(1708)$ \\
\hline Mozambique & ICAP at Columbia University & 1062 & $59(24)$ \\
\hline Nigeria & $\begin{array}{l}\text { AFENET and National Primary Healthcare } \\
\text { Development Agency (NPHCDA) }\end{array}$ & 5968 & 2979 (2979) \\
\hline Rwanda & ICAP at Columbia University & 418 & $148(138)$ \\
\hline Sierra Leone & ICAP at Columbia University & 332 & $7(0)$ \\
\hline South Sudan & ICAP at Columbia University & 804 & $24(6)$ \\
\hline Tanzania & ICAP at Columbia University & 158 & $52(24)$ \\
\hline Uganda & Infectious Diseases Institute & 13455 & 976 (729) \\
\hline Zambia & ICAP at Columbia University & 479 & $128(111)$ \\
\hline Zimbabwe & Biomedical Research and Training Institute & 3179 & $888(751)$ \\
\hline Total & & 42058 & 8444 (7574) \\
\hline
\end{tabular}


Table 2 Baseline and endline values for screening and triage measures of primary healthcare facilities in eight countries (significant differences are noted in bold font) ${ }^{\star}$

Indicator, country $(\mathbf{n}$,

number of health facilities) Baseline value, $\%(95 \% \mathrm{Cl}) \quad$ Endline value, $\%(95 \% \mathrm{Cl}) \quad$ Difference, $\%(95 \% \mathrm{Cl})$

Outdoor triage and screening area with adequate space between persons

\begin{tabular}{|c|c|c|c|}
\hline Angola $(n=28)$ & 50.0 (31.5 to 68.5$)$ & 100.0 (100.0 to 100.0$)$ & $50.0(31.5$ to 68.5$)$ \\
\hline Eswatini $(n=32)$ & 87.5 (76.0 to 99.0$)$ & 93.8 (85.3 to 102.1$)$ & $6.3(-7.9$ to 20.4$)$ \\
\hline Lesotho $(n=21)$ & 100.0 (100.0 to 100.0$)$ & $100.0(100.0$ to 100.0$)$ & 0 \\
\hline Liberia† (n=74) & 49.6 (37.2 to 60.03$)$ & 95.9 (91.4 to 100.4$)$ & 47.2 (35.1 to 59.5 ) \\
\hline Malawi $(n=42)$ & 78.6 (66.2 to 91.0$)$ & 100.0 (100.0 to 100.0$)$ & 21.4 (9.0 to 33.8$)$ \\
\hline Nigeria $(n=1281)$ & 58.6 (55.9 to 61.3 ) & 54.9 (52.2 to 57.6$)$ & $-3.8(-0.001$ to 7.6$)$ \\
\hline South Sudan $(n=18)$ & $100.0(100.0$ to 100.0$)$ & $100.0(100.0$ to 100.0$)$ & 0 \\
\hline Uganda† $(n=521)$ & 50.3 (46.0 to 54.6 ) & 86.9 (84.1 to 89.8$)$ & 36.7 (31.5 to 41.8$)$ \\
\hline All facilities $(n=2017)$ & 57.7 (55.5 to 59.8 ) & 67.5 (65.4 to 69.5$)$ & 9.8 (6.8 to 12.8$)$ \\
\hline
\end{tabular}

Dedicated triage and screening personnel trained and in place

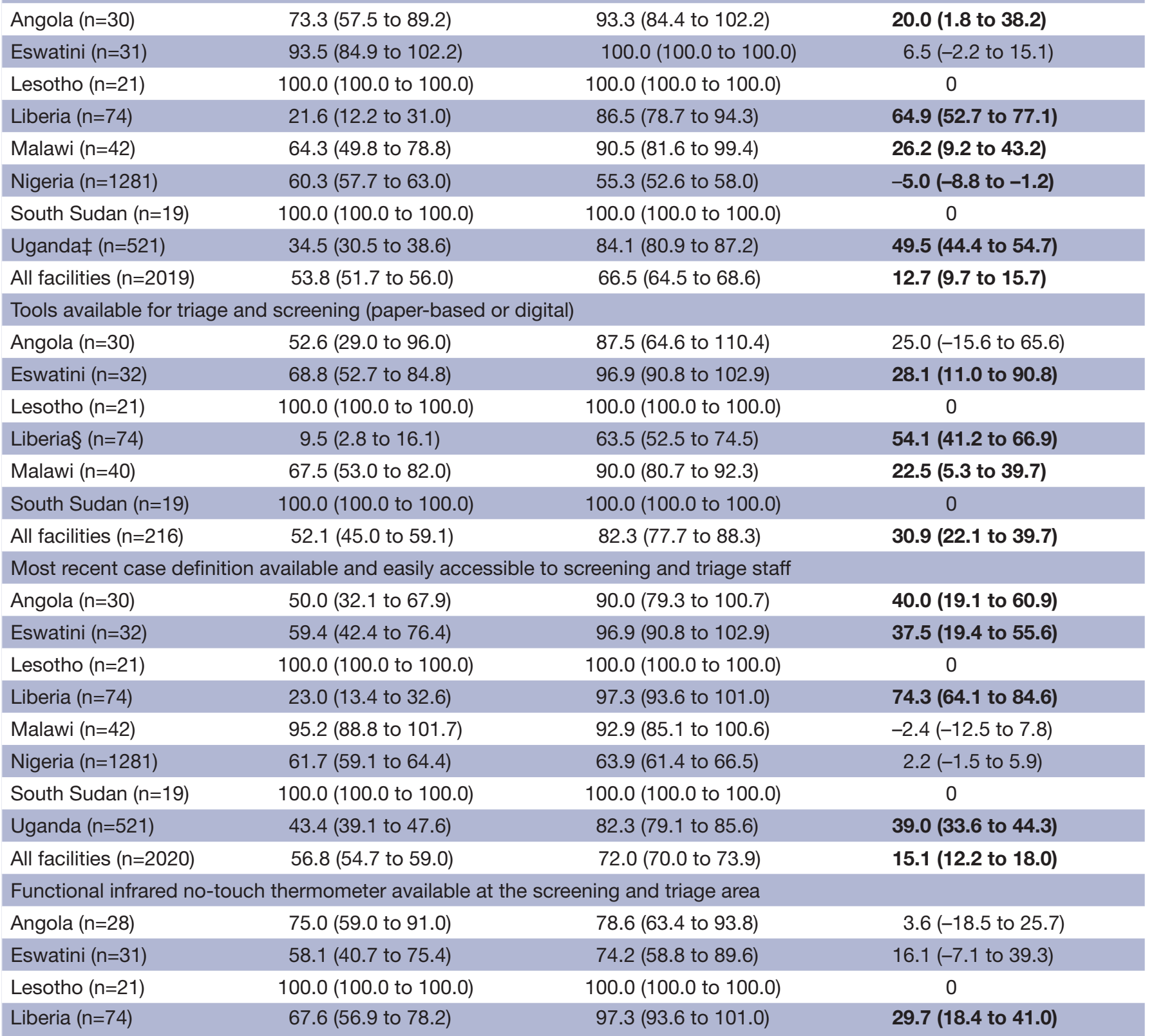


Table 2 Continued

\begin{tabular}{|c|c|c|c|}
\hline $\begin{array}{l}\text { Indicator, country ( } \mathrm{n} \text {, } \\
\text { number of health facilities) }\end{array}$ & Baseline value, $\%(95 \% \mathrm{Cl})$ & Endline value, \% $(95 \% \mathrm{Cl})$ & Difference, \% (95\% Cl) \\
\hline Malawi $(n=42)$ & 33.3 (19.1 to 47.6$)$ & 69.0 (55.1 to 83.0) & 35.7 (15.7 to 55.7$)$ \\
\hline Nigeria $(n=1281)$ & 19.7 (17.5 to 21.8$)$ & 18.1 (16.1 to 20.2$)$ & $-1.5 \%(-4.5 \%$ to $1.5 \%)$ \\
\hline South Sudan $(n=19)$ & $100.0(100.0$ to 100.0$)$ & $100.0(100.0$ to 100.0$)$ & 0 \\
\hline Uganda $(n=521)$ & 59.1 (54.9 to 63.3$)$ & 67.9 (63.9 to 72.0$)$ & 8.8 (3.0 to 14.6$)$ \\
\hline All facilities ( $n=2017)$ & 34.9 (32.8 to 36.9$)$ & 37.9 (35.8 to 40.0$)$ & $3.0(0.001$ to 6.0$)$ \\
\hline
\end{tabular}

*Not every country reported on each indicator, and even within countries, not every health facility reported on each indicator.

†The indicator used in Liberia and Uganda did not specify whether the screening and triage area was outdoors.

$\ddagger$ The indicator used was 'Is there a dedicated trained screener on duty?'.

$\S$ The indicator used was availability of 1 month's supply of screening tools at the healthcare facility for screening all staff, patients and visitors.

respectively. By project end, behaviour improved with $68 \%$ and $74 \%$ of HCWs following hand hygiene procedures and mask use, respectively. Data from Cameroon also showed improvement-hand hygiene compliance increased from $51 \%$ at baseline to $93 \%$ at endline, and mask use increased by 42 percentage points. In Liberia, staff at 31 of 87 health facilities (36\%) used appropriate PPE to conduct screening and triage at baseline compared with 72 of 76 health facilities (95\%) at endline.

\section{HEALTH FACILITY DATA USE FOR PERFORMANCE MONITORING}

Implementing partners longitudinally collected facilitylevel data to provide structured feedback to health facilities, monitor programme progress and identify persistent gaps. Appropriate screening and triage of all persons entering health facilities were emphasised as an environmental and administrative measure that could help to maintain essential services in primary health facilities. The proportion of health facilities with COVID-19 screening and triage areas significantly increased from $58 \%$ at baseline to $68 \%(\mathrm{p}<0.001)$ (table 2$)$.

We saw similar levels of improvement for other screening and triage indicators, including availability of dedicated screening and triage personnel $(+13 \%)$, availability of screening and triage tools $(+31 \%)$, most recent case definitions $(+15 \%)$ and functional infrared thermometers $(+3 \%)$. While paired facility data were not available from Cameroon, a higher proportion of facilities reported having outdoor screening and triage areas, trained screening and triage personnel, and functional infrared thermometers at endline.

Despite these improvements, the majority $(62 \%)$ of facilities included in the analysis reported not having functional infrared thermometers at endline, mostly driven by the large proportion of health facilities in the sample that were in Nigeria where bottlenecks in distribution contributed to the lack of availability. Additionally, in Nigeria, some measures of screening and triage decreased during project implementation as personnel and resources were repurposed during intervals between pandemic waves to focus on essential service delivery.
Some countries, including Lesotho and South Sudan, scored very high even at baseline and did not show significant improvements; these facilities were supported by implementing partners prior to programme inception and might not be representative of all facilities in those countries. In Liberia, LMH donors redirected preCOVID project funds to emergency response, particularly to secure PPE for health facilities.

Availability of hand hygiene materials, appropriate PPE and cleaning materials varied by country and highlight the importance of sustained investments in these items (table 3).

By project end, $85 \%$ of health facilities $(+4 \%)$ had functional handwashing stations at all points of care, and $79 \%$ of facilities $(+6 \%)$ had alcohol-based hand rub available. However, medical and surgical mask availability decreased significantly from baseline to endline, and at neither point were masks available at the majority of health facilities. Similarly, eye protection was available in only $17 \%$ of facilities by programme end, although there was no significant change from baseline to endline; a similar pattern was observed for availability of cleaning supplies. In Cameroon, the proportion of facilities with functional handwashing stations and masks increased at endline. The programme provided for PPE procurement, but not in sufficient quantities to sustainably stock health facilities for the duration of the pandemic. Although commodities were scarce, we saw significant improvements $(+16 \%)$ in appropriate cleaning and disinfection of frequently touched surfaces in health facilities, reinforcing the value of training and supportive supervision.

\section{SURVEILLANCE FOR COVID-19}

A total 2265104 patients were screened for COVID-19 symptoms on entrance to monitored health facilities in Angola, Cameroon, Eswatini, Lesotho, Malawi, Nigeria and South Sudan. These data were not available from facilities in Liberia, but these facilities did report the number of patients reported to local surveillance personnel and the number of patients referred to the next level of care. In these eight countries, among monitored health 
Table 3 Baseline and endline values for infection prevention and control measures of primary healthcare facilities in eight countries (significant differences are noted in bold font)*

\section{Indicator, country}

( $n$, number of health

facilities)

Baseline value, \% (95\% Cl)

Endline value, \% (95\% Cl)

Difference, $\%(95 \% \mathrm{Cl})$

Functional handwashing stations or ABHR available and usable at each point of care

Angola $(\mathrm{n}=28)$

Eswatini $(n=30)$

Lesotho $(n=21)$

Liberia† $(n=74)$

Malawi $(n=41)$

Nigeriał $(n=1281)$

South Sudan $(n=19)$

Uganda $(n=521)$

All facilities $(n=2015)$

96.3 (89.2 to 103.4)

96.7 (90.2 to 103.1$)$

100.0 (100.0 to 100.0)

77.0 (67.4 to 86.6$)$

87.8 (77.8 to 97.8$)$

74.8 (72.4 to 77.2$)$

100.0 (100.0 to 100.0$)$

91.0 (88.5 to 93.4$)$

ABHR available at time of site visit§

\begin{tabular}{|c|c|c|c|}
\hline Angola $(n=30)$ & 76.7 (61.5 to 91.8$)$ & 66.7 (49.8 to 83.5$)$ & $-10.0(-32.7$ to 12.7$)$ \\
\hline Eswatini $(n=32)$ & $81.3(67.7$ to 94.8$)$ & 84.4 (71.8 to 97.0$)$ & $3.1(-15.3$ to 21.6$)$ \\
\hline Lesotho $(n=21)$ & 100.0 (100.0 to 100.0$)$ & 100.0 (100.0 to 100.0$)$ & 0 \\
\hline Liberia $(n=74)$ & 20.3 (11.1 to 29.4$)$ & 78.4 (69.0 to 87.8$)$ & 58.1 (45.0 to 71.2$)$ \\
\hline Malawi $(n=42)$ & 46.3 (31.1 to 61.6$)$ & $61.0(46.0$ to 75.9$)$ & $14.6(-6.7$ to 36.0$)$ \\
\hline Nigeria $(n=1281)$ & 75.8 (73.4 to 78.1$)$ & 79.5 (77.3 to 81.7$)$ & 3.7 (5.2 to 6.9$)$ \\
\hline All facilities $(n=1480)$ & 72.7 (70.4 to 75.0$)$ & 79.1 (77.0 to 81.1$)$ & 6.4 (3.4 to 9.4$)$ \\
\hline \multicolumn{4}{|c|}{ Medical/surgical masks available at time of site visit§ } \\
\hline Angola $(n=30)$ & 80.0 (65.7 to 94.3$)$ & $90.0(79.3$ to 100.7$)$ & $10.0(-7.8$ to 27.9$)$ \\
\hline Eswatini $(n=32)$ & 39.4 (42.4 to 76.4$)$ & 96.9 (90.8 to 102.9) & 37.5 (19.4 to 55.6$)$ \\
\hline Lesotho $(n=21)$ & 100.0 (100.0 to 100.0$)$ & 90.5 (77.9 to 103.0$)$ & $-9.5(-22.1$ to 3.0$)$ \\
\hline Liberia $(n=74)$ & $81.1(72.2$ to 90.0$)$ & 89.2 (82.1 to 96.3$)$ & $8.1(-3.3$ to 19.5$)$ \\
\hline Malawi $(n=41)$ & 65.9 (51.3 to 80.4$)$ & 100.0 (100.0 to 100.0$)$ & 34.1 (19.6 to 48.7$)$ \\
\hline Nigeria $(n=1281)$ & $43.3(40.6$ to 46.0$)$ & $33.3(30.7$ to 35.8$)$ & $-10.1(-13.8$ to -6.4$)$ \\
\hline All facilities $(n=1479)$ & 48.0 (45.5 to 50.6$)$ & 41.0 (38.6 to 43.5$)$ & $-7.0(-10.5$ to -3.4$)$ \\
\hline \multicolumn{4}{|c|}{ Eye protection (face shields or goggles) available at time of site visit§ } \\
\hline Angola $(n=30)$ & 0.0 (0.0 to 0.0$)$ & 37.5 (4.0 to 71.0$)$ & 37.5 (4.0 to 71.0$)$ \\
\hline Eswatini $(n=32)$ & 75.0 (60.0 to 90.0$)$ & 100.0 (100.0 to 100.0$)$ & 25.0 (10.0 to 40.0$)$ \\
\hline Lesotho $(n=21)$ & 100.0 (100.0 to 100.0$)$ & 100.0 (100.0 to 100.0$)$ & 0 \\
\hline Liberia $(n=74)$ & 83.8 (75.4 to 92.2$)$ & 89.2 (82.1 to 96.3 ) & $5.4(-5.5$ to 16.4$)$ \\
\hline Malawi $(n=36)$ & 38.9 (23.0 to 54.8$)$ & 66.7 (51.3 to 82.1$)$ & 27.8 (5.6 to 49.9$)$ \\
\hline Nigeria $(n=1281)$ & $11.4(9.7$ to 13.3$)$ & $8.0(6.5$ to 9.5$)$ & $-3.4(-5.7$ to -1.1$)$ \\
\hline $\begin{array}{l}\text { All facilities excluding } \\
\text { Nigeria }(n=193)\end{array}$ & 18.4 (16.4 to 20.4$)$ & 16.9 (15.0 to 18.8$)$ & $-1.5(-4.3$ to 1.2$)$ \\
\hline \multicolumn{4}{|c|}{ Required cleaning supplies available at time of site visitๆ } \\
\hline Angola $(n=30)$ & $73.3(57.5$ to 89.2$)$ & $83.3(70.0$ to 96.7$)$ & $10.0(-10.7$ to 30.7$)$ \\
\hline Eswatini $(n=31)$ & 93.3 (84.4 to 102.2 ) & 96.7 (90.2 to 103.1$)$ & $3.3(-7.6$ to 14.3$)$ \\
\hline Lesotho $(n=21)$ & 100.0 (100.0 to 100.0$)$ & 100.0 (100.0 to 100.0$)$ & 0 \\
\hline Malawi $(n=42)$ & 78.6 (66.2 to 91.0$)$ & 81.0 (69.1 to 92.8$)$ & $2.4(-14.8$ to 19.6$)$ \\
\hline Nigeria $(n=1281)$ & $11.4(10.0$ to 13.1$)$ & 7.5 (6.1 to 8.9) & $-3.9(-6.2$ to -1.7$)$ \\
\hline South Sudan $(n=19)$ & 100.0 (100.0 to 100.0$)$ & 100.0 (100.0 to 100.0$)$ & 0 \\
\hline Uganda $(n=521)$ & 91.0 (88.5 to 93.4$)$ & 96.2 (94.5 to 97.8$)$ & $5.2(2.2$ to 8.1$)$ \\
\hline
\end{tabular}

Continued

$3.7(-3.4$ to 10.8$)$

$3.3(-3.1$ to 9.8$)$

100.0 (100.0 to 100.0$)$

100.0 (100.0 o 100.0)

95.9 (91.5 to 100.4)

18.9 (8.3 to 29.5)

100.0 (100.0 to 100.0 )

12.2 (2.2 to 22.2)

76.9 (74.7 to 79.2)

100.0 (100.0 to 100.0)

98.5 (97.4 to 99.5)

7.4 (4.8 to 10.2)

4.2 (1.8 to 6.5$)$

84.6 (83.0 to 86.2)

66.7 (49.8 to 83.5)

$2.2(-1.1$ to 5.4$)$

0

$0.0(-32.7$ to 12.7$)$

58.1 (45.0 to 71.2 )

(5.2 to 6.9$)$

All facilities $(n=1480)$

(79.3 to 100.7)

37.5 (19.4 to 55.6)

34.1 (19.6 to 48.7)

$-10.1(-13.8$ to -6.4$)$

$-7.0(-10.5$ to -3.4$)$

37.5 (4.0 to 71.0$)$

0

$-1.5(-4.3$ to 1.2$)$

$10.0(-10.7$ to 30.7$)$

(-7.6 to 14.3$)$

$2.4(-14.8$ to 19.6$)$

5.2 (2.2 to 8.1) 
Table 3 Continued

\begin{tabular}{|c|c|c|c|}
\hline $\begin{array}{l}\text { Indicator, country } \\
\text { (n, number of health } \\
\text { facilities) }\end{array}$ & Baseline value, \% (95\% Cl) & Endline value, \% (95\% Cl) & Difference, \% (95\% Cl) \\
\hline All facilities $(n=1945)$ & $38.2(36.1$ to 40.4$)$ & 36.7 (34.5 to 38.8$)$ & $-1.6(-4.6$ to 1.5$)$ \\
\hline \multicolumn{4}{|c|}{ Frequently touched surfaces of consultation/examination areas are cleaned and disinfected at least two times per day } \\
\hline Angola $(n=30)$ & 70.0 (53.6 to 86.4$)$ & 93.3 (84.4 to 102.3$)$ & $23.3(4.7$ to 42.0$)$ \\
\hline Eswatini $(n=30)$ & 70.0 (53.6 to 86.4$)$ & 100.0 (100.0 to 100.0$)$ & 30.0 (13.6 to 46.4$)$ \\
\hline Lesotho $(n=21)$ & $100.0(100.0$ to 100.0$)$ & 100.0 (100.0 to 100.0) & 0 \\
\hline Liberia $(n=74)$ & 31.1 (20.5 to 41.6$)$ & 95.9 (91.5 to 100.4$)$ & 64.9 (53.4 to 76.3$)$ \\
\hline Malawi $(n=42)$ & 71.4 (57.8 to 85.1$)$ & 92.9 (85.1 to 100.6$)$ & 21.4 (5.7 to 37.2 ) \\
\hline Nigeria $(n=1281)$ & 61.8 (59.2 to 64.5$)$ & 68.1 (65.6 to 70.6 ) & 6.3 (2.6 to 9.9$)$ \\
\hline Uganda $(n=521)$ & 55.1 (50.8 to 59.4 ) & 86.0 (83.0 to 89.0 ) & 30.9 (25.7 to 36.1$)$ \\
\hline All facilities $(n=1999)$ & 59.8 (57.6 to 61.9$)$ & 75.4 (73.5 to 77.2 ) & $15.6(12.7$ to 18.4$)$ \\
\hline
\end{tabular}

${ }^{*}$ Not every country reported on each indicator, and even within countries, not every health facility reported on each indicator.

†The indicator was availability of hand hygiene stations at all points of care.

$\ddagger$ The indicator was availability of functional handwashing stations.

§Values recoded to binary based on different forms of country reporting; availability at the time of visit of $>0$ items coded as 1 .

IBuckets, mops, cleaning cloths and disinfectant solution (eg, bleach) all available.

ABHR, alcohol-based hand rub.

facilities, 15143 patients were reported to local surveillance personnel, and 3482 patients were referred to the next level of care.

We collected data on the number of incident suspected HCW infections at the facility level, as well as the number of unique HCWs reporting to work at the facility and used these data to develop a proxy indicator of suspected HCW infections during the reporting period (table 4).

Seven countries contributed data on suspected HCW infections, and Liberia reported confirmed infections. There were 1468 suspected COVID-19 infections among HCW in monitored facilities, including 55 confirmed infections in Liberia. There were some delays in reporting data, but based on reporting dates, the proportion of HCWs with suspected infections was lowest in May, peaked in July and decreased by September. The peak in suspected COVID-19 infections was coincident with the peak of the first wave of COVID-19 in the African continent. HCWs among monitored health facilities may have been suspected of infection more than once during the project period, and early in the pandemic, the suspected case definition was broader. Although our data on suspected COVID-19 cases may be an overestimate, they indicate that during the height of the pandemic, a substantial proportion of HCWs at primary health facilities were at risk of infection.

\section{LESSONS LEARNED AND RECOMMENDATIONS}

The COVID-19 pandemic has taken a significant toll on health systems, but effective IPC programmes may help mitigate these impacts. During the Ebola epidemic, supportive

Table 4 Suspected COVID-19 infections among HCWs and average number of health workers reporting to work by date of report -8 countries, May-November 2020*

\begin{tabular}{|llll}
\hline & $\begin{array}{l}\text { Suspected COVID-19 } \\
\text { infections among } \\
\text { monitored facilities } \\
\text { (monthly total n) }\end{array}$ & $\begin{array}{l}\text { HCWs reporting to work } \\
\text { among monitored facilities } \\
\text { (monthly average total } n \text { ) }\end{array}$ & $\begin{array}{l}\text { Monthly average percentage } \\
\text { of total number of HCWs with } \\
\text { suspected COVID-19 infections } \\
\text { among monitored facilites }\end{array}$ \\
\hline May & 50 & 4262 & 1.2 \\
\hline June & 365 & 1537 & 23.7 \\
\hline July & 684 & 1650 & 41.5 \\
\hline August & 268 & 2055 & 13.0 \\
\hline September & 79 & 3186 & 2.5 \\
\hline October & 0 & 303 & 0 \\
\hline November & 22 & 1182 & 1.9 \\
\hline
\end{tabular}

*Data on HCW infections were not collected as part of the programme in Uganda; Liberia reported confirmed HCW infections.

$\mathrm{HCW}$, healthcare worker. 
supervision and monitoring likely contributed to improved IPC practices at healthcare facilities, ${ }^{21}$ and improved IPC practices likely contributed to a reduction in the proportion of HCW infections from 12\% in July 2014 to $1 \%$ in February 2015 . $^{5}$ Training and education on IPC was shown to decrease the risk of SARS-CoV-1 and MERS-CoV infection among HCWs ${ }^{22}$ and asymptomatic HCWs trained on protection against SARS-CoV-2 early in the pandemic were less likely to test positive. ${ }^{23}$ In our initiative, the combination of training, monitoring and provision of resources may have contributed to short-term improvements in IPC performance at the health facility level.

A major component of our initiative was training HCWs on IPC with a focus on COVID-19. However, development and maintenance of a trained health workforce should be supported through inclusion of IPC in training curricula at all levels, rather than within individual disease-specific programmes. Integration of IPC training in curricula for medical, nursing and other health professional students and established career pathways for IPC professionals can strengthen IPC capacity at national and subnational levels. ${ }^{36}$

Monitoring of IPC practices at the health facility level is also critical to assess performance, identify gaps and provide structured feedback to health facilities to facilitate improvements. ${ }^{2}$ Aggregate health facility data should be used to guide evidence-based decision making at the national level. Implementing partners used checklist data to guide improvements at the facility level, including provision of PPE. However, a limitation of our checklist was the lack of measures of HCW behaviours, including appropriate use of PPE and hand hygiene adherence. To address those limitations, RTSL partnered with Africa CDC, the WHO Regional Office for Africa and ICAN to develop a continent-wide monitoring tool incorporating these critical behaviours that are amenable to training and mentorship.

The COVID-19 pandemic has further highlighted critical gaps in infrastructure and resource availability globally, in particular PPE. ${ }^{32} 3738$ We saw short-term improvements in IPC performance, including availability of outdoor screening and triage areas with adequate physical distancing, but gaps remain, including PPE availability. Procurement and local production of PPE needs to increase, with donor and domestic investment in equitable distribution reaching the primary healthcare level and the 'last mile', including community health workers. These commodity gaps likely contributed to the high level of HCW infections observed during the peak of the first wave of the pandemic in Africa, although the source of infections (facility or community) is not discernible from our available data.

Improving IPC practices during outbreaks is important to response efforts, but our findings demonstrate that acute response efforts are not sufficient. IPC programmes should be prioritised as part of overall health system preparedness. National IPC policies should include primary health facilities as critical vehicles for essential service delivery and disease surveillance. There is a need for ongoing investment to prevent, detect and respond to public health risks, including outbreaks, particularly in LMICs. ${ }^{39}$ Joint external evaluation (JEE) data indicate limited IPC capacity across the WHO African region, ${ }^{40}$ likely due to financial constraints, lack of infrastructure and administrative support, and poor implementation and regulation of IPC programmes. ${ }^{41}$ Addition of a dedicated JEE technical area on safer health facilities would provide more comprehensive assessments of IPC capacity and WASH implementation and guide longer term, sustainable investments to ensure safe, high-quality health service delivery. ${ }^{42}$

Our data on suspected infections may be an overestimate but suggest that HCWs are at increased risk of infection. However, there is no global systematic record of HCW infections and deaths. ${ }^{27}$ The WHO Regional Office for Africa Integrated Disease Surveillance and Response (IDSR) ${ }^{43}$ strategy could be leveraged to monitor health facility-level surveillance for SARS-CoV-2 and other infectious diseases among HCWs. Adopting a new variable for occupational exposure to existing IDSR case-based investigation forms could facilitate routine data collection and reporting. Data would allow for prompt outbreak responses and inform national programmes, policies and resource mobilisation efforts.

There are some limitations to our data. First, the healthcare facilities included in our initiative have received support from implementing partners; thus, IPC capacities measured at baseline and follow-up are positively biased and not indicative of national programme performance. Second, these facilities represent a small proportion of all health facilities in each country, and data may not be generalisable. Third, in some countries, not every facility was able to report on each indicator, limiting our ability to accurately assess overall IPC capacity. Despite these limitations, these data highlight the need for comprehensive, multimodal strategies to strengthen IPC programmes.

\section{CONCLUSION}

The COVID-19 pandemic has demonstrated the fragility of health systems globally, and the direct and indirect impact on health systems has been profound. Our response efforts, including training, monitoring and provision of resources, likely contributed to short-term improvements in IPC capacity and HCW behaviours. However, efforts to improve IPC programmes need to continue beyond acute response efforts. Comprehensive, funded IPC policies need to be adopted and implemented to protect HCWs and the patients they serve and ultimately to contribute to safe health services delivery.

\section{Author affiliations}

${ }^{1}$ Prevent Epidemics, Resolve to Save Lives, an Initiative of Vital Strategies, New York, New York, USA

${ }^{2}$ The Alliance for International Medical Action (ALIMA), Yaoundé, Cameroon ${ }^{3}$ Nigeria Country Office, African Field Epidemiology Network (AFENET), Abuja, Nigeria

${ }^{4}$ Infectious Diseases Institute (IDI), McKinnell Knowledge Center, College of Health Sciences, Makerere University, Kampala, Uganda

${ }^{5}$ Liberia Country Office, Last Mile Health, Monrovia, Liberia 
${ }^{6}$ ICAP at Columbia University, Mailman School of Public Health, New York, New York, USA

${ }^{7}$ Infection Control Africa Network, Cape Town, South Africa

Acknowledgements We thank our implementing partners for their efforts in implementing this initiative. Our implementing partners include ALIMA, AFENET, National Primary Health Care Development Agency-Nigeria, Biomedical Research and Training Institute, Ethiopian Medical Association, ICAP at Columbia University, Infection Control Africa Network, Infectious Diseases Institute at Makerere University, Jhpiego, Last Mile Health and Muso.

Collaborators Ramatu Abdu-Aguye; Usman Gana Abdulkadir; Usman Saidu Adamu; Olugbemiga Aina; Jackson Amone; Philip Bammeke; Bakunawa Garba Bello; Karen Brudney; Sae-Rom Chae; António Cristóvão; Eunice Damisa; Georges Alain Etoundi Mballa; Ntombi Ginindza; Nkwan Jacob Gobte; Benjamin Grant; Kieran Hartsough; Shambel A. Hussen; Andrew Kambugu; Harrison Kamiru; Jones Kaponda Masiye; Felix Kayigamba; Richard Lako; Stephen Macheso; Limpho Maile; Olivier Manzi; Joana Maria; Susan Michaels-Strasser; Lucy Moe; Lumbani Munthali; Naomi Mviha; Gerald Mwima; Felix Ndagije; Isilda Neves; Patrick Nguku; Folasade Ogunsula; Solome Okware; Charles Olaro; Ibrahim Suleiman Ozaki; Miriam Rabkin; Mantue Reeves; T. Ruston Yarnko; Ruben Sahabo; Faisal Shuaib; Likelay Tehmeh; Lyson Tenthani; Marshall Thomas; Belinda Ubar; Gideon Ugbenyo; Onyekachi Ukaejiofo; Chukwuma David Umeokonkwo; George Upenytho; Debra Vambe; Chea Sanford Wesseh; Habtamu Ayalneh Worku

Contributors CTL conceived and designed the analysis and conducted the data analysis. RI, MK, ML, MS, FT and AV contributed data to the manuscript. CTL, LNP and SK interpreted the data. All coauthors contributed to the drafting of the manuscript and reviewed and approved the final manuscript.

Funding The Resolve to Save Lives Health Care Worker Training Initiative was funded by Bloomberg Philanthropies and the Stavros Niarchos Foundation. Funding was provided via Resolve to Save Lives to Implementing Partners to implement the initiative.

Competing interests The Resolve to Save Lives Health Care Worker Training Initiative was funded by Bloomberg Philanthropies and the Stavros Niarchos Foundation. Funding was provided via Resolve to Save Lives to Implementing Partners to implement the initiative.

\section{Patient consent for publication Not required.}

Ethics approval The project was determined to be non-human subjects research by the Human Protection Administrator at Vital Strategies and the Columbia University Medical Center Institutional Review Board (protocol \#AAAT1968). Appropriate ethical and ministry of health approvals were obtained in each country contributing facilitylevel data to this article.

Provenance and peer review Not commissioned; externally peer reviewed.

Data availability statement All data relevant to the study are included in the article.

Supplemental material This content has been supplied by the author(s). It has not been vetted by BMJ Publishing Group Limited (BMJ) and may not have been peer-reviewed. Any opinions or recommendations discussed are solely those of the author(s) and are not endorsed by BMJ. BMJ disclaims all liability and responsibility arising from any reliance placed on the content. Where the content includes any translated material, BMJ does not warrant the accuracy and reliability of the translations (including but not limited to local regulations, clinical guidelines, terminology, drug names and drug dosages), and is not responsible for any error and/or omissions arising from translation and adaptation or otherwise.

Open access This is an open access article distributed in accordance with the Creative Commons Attribution Non Commercial (CC BY-NC 4.0) license, which permits others to distribute, remix, adapt, build upon this work non-commercially, and license their derivative works on different terms, provided the original work is properly cited, appropriate credit is given, any changes made indicated, and the use is non-commercial. See: http://creativecommons.org/licenses/by-nc/4.0/.

\section{REFERENCES}

1 World Health Organization (WHO). Health workforce [Internet]. Available: https://www.who.int/health-topics/health-workforce\#tab= tab_1 [Accessed 2020 Sep 14]

2 World Health Organization (WHO). Minimum requirements for infection prevention and control (IPC) programmes. Geneva, 2019.
3 Allegranzi B, Donaldson LJ, Kilpatrick C, et al. Infection prevention: laying an essential foundation for quality universal health coverage. Lancet Glob Health 2019;7:e698-700.

4 World Health Organization. Report on the burden of endemic health care-associated infection worldwide clean care is safer care. Geneva, 2011.

5 WHO. Health worker Ebola infections in guinea, Liberia and Sierra Leone: a preliminary report. Geneva, 2015.

6 Evans DK, Goldstein M, Popova A. The Next Wave of Deaths from Ebola? The Impact of Health Care Worker Mortality [Internet] Washington DC, 2015. Available: http://econ.worldbank.org

7 World Health Organization (WHO). Summary of probable SARS cases with onset of illness from 1 November 2002 to 31 July 2003 [Internet], 2015. Available: https://www.who.int/csr/sars/country/ table2003 09_23/en/ [Accessed 2020 Aug 3].

8 CDC COVID-19 Response Team. Characteristics of Health Care Personnel with COVID-19 - United States, February 12-April 9, 2020. MMWR Morb Mortal Wkly Rep 2020;69:477-81.

9 Remuzzi A, Remuzzi G. COVID-19 and Italy: what next? Lancet 2020;395:1225-8.

10 World Health Organization (WHO). Coronavirus Weekly Epidemiological Update - 12 October 2020 [Internet]. Geneva, 2020. Available: https://www.who.int/docs/default-source/coronaviruse/ situation-reports/20201012-weekly-epi-update-9.pdf

11 Nguyen LH, Drew DA, Graham MS, et al. Risk of COVID-19 among front-line health-care workers and the general community: a prospective cohort study. Lancet Public Health 2020;5:e475-83.

12 Bandyopadhyay S, Baticulon RE, Kadhum M, et al. Infection and mortality of healthcare workers worldwide from COVID-19: a systematic review. BMJ Glob Health 2020;5:3097.

13 WHO Regional Office for Africa. Weekly Bulletin on outbreaks and other emergencies week 15: 5-11 April 2021, 2020. Available: https://apps.who.int/iris/bitstream/handle/10665/340773/OEW150511042021.pdf [Accessed 2021 Apr 20].

14 Talisuna A, Yoti Z, Lee C, et al. The urgent need for a global commitment to protect healthcare workers. BMJ Glob Health 2020;5:e004077.

15 Elston JWT, Cartwright C, Ndumbi P, et al. The health impact of the 2014-15 Ebola outbreak. Public Health 2017:143:60-70.

16 Ribacke KJB, Saulnier DD, Eriksson A. Effects of the West Africa Ebola virus disease on health-care utilization - A systematic review. Front Public Heal 2016;4:222.

17 World Health Organization. Pulse survey on continuity of essential health services during the COVID-19 pandemic: interim report, 27 August 2020. Geneva, 2020.

18 PERC. Responding to COVID-19 in African Countries: Analysis and Report of Survey Findings [Internet], 2020. Available: https://www. ipsos.com/sites/default/files/ct/publication/documents/2020-09/ executive-summary-cross-national-survey-31-august-2020.pdf

19 Elston JWT, Moosa AJ, Moses F. Impact of the Ebola outbreak on health systems and population health in Sierra Leone. J Public Health 2015;38:fdv158.

20 Wang X, Ferro EG, Zhou G, et al. Association between universal masking in a health care system and SARS-CoV-2 positivity among health care workers. JAMA 2020;324:703-4.

21 Ephraim O-E, Cyrus S, Myer P. The impact of supportive supervision of infection prevention and control practices on Ebola outbreak in Liberia. J Infect Prev 2018;19:287-93.

22 Chou R, Dana T, Buckley DI, et al. Epidemiology of and risk factors for coronavirus infection in health care workers: a living rapid review. Ann Intern Med 2020;173:120-36.

23 Zhou F, Li J, Lu M, et al. Tracing asymptomatic SARS-CoV-2 carriers among 3674 hospital staff:a cross-sectional survey. EClinicalMedicine 2020;26:100510.

24 Assefa J, Diress G, Adane S. Infection prevention knowledge, practice, and its associated factors among healthcare providers in primary healthcare unit of Wogdie district, northeast Ethiopia, 2019: a cross-sectional study. Antimicrob Resist Infect Control 2020;9:136.

25 Adegboye MB, Zakari S, Ahmed BA, et al. Knowledge, awareness and practice of infection control by health care workers in the intensive care units of a tertiary hospital in Nigeria. Afr Health Sci 2018;18:72-8.

26 Tartari E, Tomczyk S, Pires D, et al. Implementation of the infection prevention and control core components at the National level: a global situational analysis. J Hosp Infect 2021:108:94-103.

27 International Council of Nurses. Protecting nurses from COVID-19 a top priority: A survey of ICN's national nursing associations, 2020

28 Manzi A, Hirschhorn LR, Sherr K, et al. Mentorship and coaching to support strengthening healthcare systems: lessons learned across the five population health implementation and training partnership projects in sub-Saharan Africa. BMC Health Serv Res 2017;17:831. 
29 Desai AN, Ramatowski JW, Lassmann B, et al. Global infection prevention gaps, needs, and utilization of educational resources: a cross-sectional assessment by the International Society for infectious diseases. Int J Infect Dis 2019;82:54-60.

30 Fischer WA, Hynes NA, Perl TM. Protecting health care workers from Ebola: personal protective equipment is critical but is not enough. Ann Intern Med 2014;161:753-4.

31 McMahon DE, Peters GA, Ivers LC, et al. Global resource shortages during COVID-19: bad news for low-income countries. PLoS Negl Trop Dis 2020;14:e0008412.

32 Garber K, Ajiko MM, Gualtero-Trujillo SM, et al. Structural inequities in the global supply of personal protective equipment. $B M J$ 2020;370:m2727.

33 Resolve to Save Lives. Best Practices for COVID-19 Integrated Health Care Worker Training in Low-Resource Settings, Including Primary Heatlh Care Sites [Internet], 2020. Available: https:// preventepidemics.org/wp-content/uploads/2020/07/CCC_022 Tools-for-Primary-Health-Centers_040720-1.pdf [Accessed 2021 Apr 20].

34 Africa Centres for Disease Control and Prevention. Best Practices for COVID-19 in Primary Healthcare Facilities - Africa CDC [Internet] Addis Ababa, 2020. Available: https://africacdc.org/download/bestpractices-for-covid-19-in-primary-healthcare-facilities/ [Accessed 2021 Apr 20].

35 Dooley SW, Frieden TR. We must rigorously follow basic infection control procedures to protect our healthcare workers from SARSCoV-2. Infect Control Hosp Epidemiol 2020;41:1438-40.
36 WHO. Guidelines on core components of infection prevention and control programmes at the National and acute health care facility level. Geneva, 2016.

37 Cohen J, Rodgers YvanderM. Contributing factors to personal protective equipment shortages during the COVID-19 pandemic. Prev Med 2020;141:106263.

38 Livingston E, Desai A, Berkwits M. Sourcing personal protective equipment during the COVID-19 pandemic. JAMA 2020;323:1912-4.

39 Kandel N, Chungong S, Omaar A, et al. Health security capacities in the context of COVID-19 outbreak: an analysis of international health regulations annual report data from 182 countries. Lancet 2020;395:1047-53.

40 World Health Organization (WHO). Joint External Evaluation (JEE) mission reports [Internet]. Available: https://www.who.int/ihr/ procedures/mission-reports/en/ [Accessed 2020 Dec 15].

41 Sastry S, Masroor N, Bearman G, et al. The 17th International Congress on infectious diseases workshop on developing infection prevention and control resources for low- and middle-income countries. Int J Infect Dis 2017;57:138-43.

42 Wilkason C, Lee C, Sauer LM, et al. Assessing and reducing risk to healthcare workers in outbreaks. Health Secur 2020;18:205-11.

43 WHO Regional Office for Africa. Integrated Disease Surveillance [Internet]. Available: https://www.afro.who.int/health-topics/ integrated-disease-surveillance [Accessed 2020 Dec 18]. 